\title{
DEPAUSING OF TAPES
}

\author{
by Richard F. Melo
}

The availability of textbook tapes from the publishers has lifted some burdens from laboratory directors and language instructors. However, regardless of origin, there always remains a problem of interfacing the software with the hardware. The tapes must work efficiently on your equipment.

I recently specified the Scribe Internationale Audio Tutor Language Laboratory for the new laboratory at the University of San Francisco. The previous lab had been installed nearly ten years ago by Fr. P. Carlo Rossi, S. J. and used the magnetic disc system. The Audio Tutor differs from most lab recorders. Instead of the basic stereo (master/student) system, the Tutor uses two separate systems, physically located on one tape-deck.

The master tape is a five-inch $33 / 4$ half-track tape. It carries only the master stimuli. The student records and hears his voice from a continuous tape loop. The pedagogical format is stimulus-responsestimulus. This is accomplished by an automatic rewind-cue function of the master tape which depends upon a pause of 2 seconds (signal drop of 16-24 db). On request the master tape will play backwards until a "pause" is sensed, stop, and replay the stimulus (word, phrase, or sentence). This same function occurs when the student records his voice on the tape loop, and hears it immediately and automatically.

During the student-record-listen function, the master tape rewinds to the pause preceding the stimulus, and waits until the student record-listen cycle is completed. Then it replays the stimulus.

Since the student-record is separate from the master tape, and since the master tape needs only a minimum of two seconds to interface with the Scribe, the standard language laboratory tape with student response time on the master tape (generally one-and-a-half times the stimulus) has more dead time than necessary. The problem is to depause the master tapes, shortening every pause to two seconds. Considerable tape-saving is obtained and operations are simplified, since the number of tapes on hand can be reduced. To manually depause the tapes is time consuming and inefficient, but a simple apparatus can be engineered to reduce the pauses automatically.

Simply stated, pauses are shortened to two seconds by a system which makes a dub of the master tape. It uses two tape-decks, one is a playback-deck for the master, and the second is a solenoid-operated 


\section{Depausing of Tapes}

deck for the dubbed copy. The playback deck is fitted with two playback heads (a three head tape deck - i.e. one with recording monitor head - will work as well.) The signal from the first head is fed through pre-amplifiers to a voice actuated switch (referred to as VOX). The VOX, in turn, controls a relay which has been interfaced with the record-stop (or pause) function on the recording tape-deck. The second head on the playback (master) machine feeds through a preamplifier to the recording head on the recording deck. The VOX is set for a two second delay. The two heads on the playback machine are necessary for inserting a mechanical delay of approximately $1 / 10$ second between sensed signal and recorded signal. This allows for mechanical starting and stopping of the recording tape deck, eliminating any flutter or wow on the dubbed tape.

The master tape is threaded onto the playback machine, and the recording machine is threaded with blank tape and placed in the record mode. When a signal is sensed by the first head on the playback (master) machine, it will activate the VOX closing (or opening as the interfacing may require) the relay. This starts the recording machine in the record mode. One-tenth of a second later, the signal will reach the second playback head on the playback (master) machine and be sent to the record-amplifier-head of the recording machine. When the signal drops (approximately $16-24 \mathrm{db}$ ) the VOX will hold the relay closed (or open) for two seconds. If no signal occurs after two seconds, the VOX relay will automatically stop the recording machine tape travel, and hold it while the master-machine continues to play. When a signal is again sensed by the first head of the master machine, the VOX will activate, starting the recording-deck once immediately followed by the recording signal. Pauses of less than twoseconds will not give the VOX time to operate, and the recorder continues recording.

Although this system is primarily used to depause tapes for the Scribe Audio Tutor, Laboratory Directors have seen the opposite problem: inserting pauses into tapes. This can be done with slight modifications. First the master-playback machine also has to be solenoid operated. The VOX will operate only the playback machine, not the recording (dubbing) machine. The VOX will operate on a very short delay (one second). A timing device will turn off the playback machine for a desired pause ( 5 or 10 seconds). Then it will de-activate the VOX and turn on the playback machine.

This system cannot create a proportional pause such as time-anda-half of the stimulus with words, phrases, or sentences. A proportional-pausing machine would be complex, but not impossible, and can be achieved with the tape decks made by Scribe which utilize the 
closed tape loop. The master tape is placed on the Scribe just as any master tape. The signal is fed to both the recording machine and the continuous tape loop. Both recording machine and loop record the master. A pause of one second, as at the end of a sentence, phrase or vocabulary word stops the motion of the master tape and activates the playback (with no output connection) of the continuous loop. The loop recording the stimulus in the exact time length requires the exact same time length to "playback". Simultaneously, the recording machine is running, and the master tape is stopped. The microswitch which automatically reactivates the movement of the master tape un. der the usual Scribe usage functions the same way - it activates the master tape after it plays the response. With very little modification, the Scribe Audio Tutor can be used to pause tapes at least on equal stimulus-pause timing. Adding an additional holding timer increases this pause to allow for slow student imitation.

Hopefully, these thoughts will encourage other laboratory directors to experiment with existing and modified equipment to help in the interfacing of software to their particular laboratory equipment.

ABOUT THE AUTHOR: Professor Richard F. Melo is director of the language laboratory at the University of San Francisco, San Francisco, California 94117. 